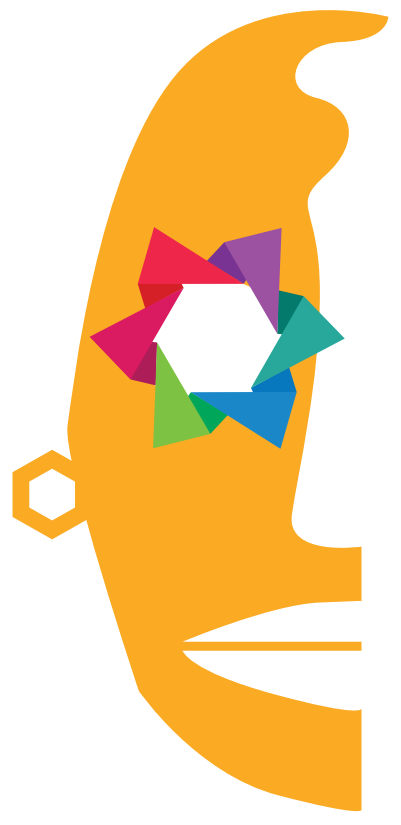

Carlos Federico Vidal Ortega

Universidad Nacional de Costa Rica

Heredia, Costa Rica

\title{
Las representaciones del Caribe en El gran zoo de Nicolás Guillén
}

\section{The representations of the Caribbean in The great zoo of Nicolás Guillén}

\section{Resumen}

El gran zoo (1984), del poeta cubano Nicolás Guillén, ofrece distintas representaciones sobre el Caribe. El artículo argumenta que el texto de Nicolás Guillén se inscribe dentro del movimiento literario hispanoamericano de la neovanguardia. Luego, se examinan algunas características formales del texto, tomando como ejemplo los poemas "El sueño" y "Guitarra". Otro poema que se estudia con más detenimiento es "El tenor", el cual parodia la división entre la alta cultura y la cultura popular. Por último, se analizan varias alusiones del poemario al contexto histórico de la Guerra Fría y la Carrera Espacial.

Palabras clave: Zoológico, neovanguardia, bestiario, Cultura Popular, Carrera Espacial.

\begin{abstract}
El gran zoo (1984), by the Cuban poet Nicolás Guillén, offers various representations of the Caribbean. The article argues that this poetry book falls within the tradition of the Post Avant-garde literary movement in Spanish America. Additionally, various formal characteristics of the text are examined, as exemplified in the poems "The Dream" and "Guitar". Another poem that receives close attention is "The Tenor", which parodies the division between high culture and popular culture. Lastly, several allusions of the poetry book to the historical context of the Cold War and the Space Race are analyzed.
\end{abstract}

Keywords: Zoo, Post Avant-garde, Bestiary, Popular Culture, Space Race. 


\section{Introducción}

El poemario El gran zoo (1984) está organizado como un zoológico. ¿Qué connota dicha palabra? En su famoso ensayo La isla que se repite (1998), el intelectual cubano Antonio Benítez Rojo lo describe como "el lugar donde los animales son exhibidos y manipulados con fines de conocimiento, de estudio, de discurso científico; es decir, para ser leídos y comentados por parte de quienes detentan el poder” (p. 165). De ahí las dos palabras que la componen, 'zoo' y 'lógico'.

Sin embargo, como ocurre con toda institución represiva, el grupo dominante fracasa en su deseo de controlar y transformar al recluso: "La máquina de poder, el zoológico o la academia militar, es un fracaso en sí misma, una imposibilidad en sí misma como hace ver Foucault” (Benítez Rojo, 1998, p. 165). ¿Por qué, entonces, eligió Guillén ambientar su poemario en una institución de esta índole? ¿Tuvo en mente una intención alegórica?

Nótese que se ha dicho 'grupo' en vez de 'especie' dominante, término usual al hablar de zoológicos. Ello se debe a que, en El gran zoo (1984), cohabitan seres de distinto estatuto ontológico. Hay fenómenos naturales y biológicos, objetos, instituciones, regiones geográficas, animales reales, actores sociales y entidades imaginarias, como el escarabajo de oro del cuento homónimo de Edgar Allan Poe.

\section{Guillén y el sistema literario hispanoamericano}

Según se desprende del epígrafe, la figura de Guillén repercutió más allá del ámbito hispanoparlante. Su poética, de una originalidad contundente, se inscribe dentro del post-vanguardismo o neovanguardia, en el sistema literario hispanoamericano.

Antes de hablar de poéticas post-vanguardistas, se deben indicar los principales postulados de la vanguardia.

En primer lugar, los poetas vanguardistas cuestionaron el estatuto de la obra de arte en la sociedad mediante la transgresión de las normas de la institución literaria (Pérez, 1992). En vez de crear aquellas imágenes elegantes y técnicamente perfectas del modernismo en términos de la métrica, acercaron el arte a la cotidianeidad. Resulta paradigmático del esfuerzo por acercar el arte a la vida cotidiana, el título del poemario de Oliveiro Girondo: Veinte poemas para ser leídos en el tranvía (1922).

En segundo lugar, los poetas vanguardistas privilegiaron el enunciado hermético, cuyo significado no dependía del mundo externo, sino de la coherencia interna. Es la época de Trilce (1922) de Vallejo y Residencia en la tierra (1933/1935) de Neruda. Este segundo postulado sería replanteado por los primeros vanguardistas, 
Vallejo y Neruda, tras el fusilamiento de García Lorca en la guerra civil española (Pérez, 1992). Eso los llevó a adoptar una poética que aludiera a la realidad social de forma más directa sin renunciar al primer postulado, lo que marca el comienzo de las poéticas post-vanguardistas.

Señalemos cuatro tendencias de las poéticas neovanguardistas que abordaron distintas problemáticas del sistema literario hispanoamericano. La poesía de Nicolás Guillén ejemplifica la primera tendencia neovanguardista: establecer vasos comunicantes entre la poesía culta y la poesía popular (Pérez, 1992). Lo anterior constituye acaso su mayor mérito literario, ya que pone en diálogo "dos sistemas culturales separados en forma y contenido" (Pérez, 1992, p. 52). Como indica Szymoniak (2011), que sigue a Augier (1974):

Lo que debe Guillén a las Vanguardias es, según Ángel Augier, «la despreocupación formal, el desdén hacia la métrica y la rima, la naturalidad rayana en prosaísmo; y que predomin[a] lo temático sobre lo metafórico, la idea sobre la imagen.» (Augier, 1974, XXIV—XXV, citado por Szymoniak, 2011, p. 117)

La segunda tendencia neovanguardista buscó reformular aquellas poéticas vanguardistas más fecundas sin renunciar totalmente a sus cánones (Pérez, 1992). Por ejemplo, en Piedra de sol (1957), Octavio Paz alternó la técnica de la escritura automática del surrealismo con elementos más lógicos y comprensibles de la historia de México (Pérez, 1992).

Vinculada a la anterior, la tercera tendencia neovanguardista alude a referentes realistas y hechos históricos (Pérez, 1992). Si bien el realismo social no pretendía incurrir en una copia de la realidad, el Homenaje a los indios americanos (1969) de Cardenal, llevó la referencialidad demasiado lejos. A veces, el exteriorismo o poesía conversacional se acercaba en demasía al registro coloquial del lenguaje, y sacrificaba la metáfora con tal de ser comprendida. Por su parte, el Canto general (1950) de Neruda le atribuía al poeta la obligación de nombrarlo todo.

Los escritores de la cuarta tendencia le achacaron al realismo social cierto historicismo y un tono demasiado serio. De ahí el éxito de ventas que tuvieron los Poemas y antipoemas (1954) de Nicanor Parra, que devolvieron a la poesía hispanoamericana su carácter lúdico e irreverente (Pérez, 1992). Tanto así, que el mismo Neruda, en Odas elementales (1954) y Estravagario (1958), exploró las posibilidades cómicas de la vida cotidiana.

Así las cosas, la trayectoria de Guillén sigue esta evolución: desde el negrismo de Motivos de son (1930) y Sóngoro Cosongo (1931), hasta textos más experimentales como El gran zoo (1984), pasando por la poesía social de La paloma de vuelo popular (1958). 


\section{Características formales de $E l$ gran zoo (1984)}

De los mecanismos indicados por Ángel Augier, en El gran zoo (1984) prevalece la transmisión clara de la idea al lector sobre las consideraciones formales como la métrica y la rima. Nancy Morejón considera que el madrigal es el verso base que estructura El gran zoo (1984). El madrigal es una forma poética que se caracteriza por combinar versos de diversa longitud. La variedad métrica obedece a la diversidad de los especímenes que habitan El gran Zoo (1984).

En general, la obra de Guillén utiliza el ritmo, las variantes tipográficas y la espacialización para organizar el discurso. A la inversa de las formas poéticas tradicionales que caracterizan la poesía social de Guillén’

El gran zoo (1984), para Margarita García Veitía, es un bestiario "en la tradición de los bestiarios de Apollinaire y Valle-Inclán” (Morejón, 1994, p. 318). Un bestiario es un género literario "entre la enciclopedia arcaica y la narración fantástica que describe una serie de animales reales e imaginarios" (Sariols Persson, 2012, p. 2). Sus orígenes se remontan a la Antigüedad. Durante la Edad Media, combinaron ciencia y fantasía, vertientes que se bifurcan a partir del Renacimiento; ya que los bestiarios van a ser relegados al estatuto de obras secundarias de autores conocidos. A menudo, los bestiarios eran escritos por filósofos como críticas veladas a la sociedad (Sariols Persson, 2012). Sin embargo, a partir del siglo XX, se recupera la vinculación entre ciencia y fantasía (Sariols Persson, 2012). Tanto en prosa como en verso se escriben bestiarios. En América Latina, uno de los bestiarios más célebres fue el Confabulario (1952) del mexicano Juan José Arreola.

En El gran zoo (1984) los entes más diversos se enuncian "con el mismo tono sosegado" (Morejón, 1994, p. 311). ¿Cómo se logra esa homologación? Mediante dos operaciones. La primera consiste en refrescar o reactualizar metáforas que han sido desemantizadas. Es el caso del poema "El tigre", en cuyo final se indica que se trata de «un tigre real». Para García Veitía (1994), esta operación "supone el cierre del pensamiento metafórico que abarca el poema", con lo cual se "va a deslexicalizar una metáfora tradicional: el tigre es menos fuerte, violento, etc. que el instinto sexual, el puñal del amor, un furioso de celos, aspectos con los que se le ha comparado muchas veces" (p. 314). Ahora bien, el poema de Guillén es un intertexto de un poema del bestiario de Borges El libro de los seres imaginarios (1960):

1 El poema que inicia La paloma de vuelo popular, "Arte poética", comprende siete redondillas. Asimismo, el poema "Cañaveral" contiene una décima. Por último, el poema "Un largo lagarto verde" sigue el esquema del romance. Durante el siglo XX, la tradición del romancero fue retomada por Federico García Lorca en el Romancero gitano (1928). En el texto señalado, García Lorca dedicó a Lydia Cabrera el poema "La casada infiel", lo que sugiere una proximidad afectiva e intelectual del escritor español hacia Cuba. 
En el poema "El otro tigre", Borges explica sin rodeos la oposición entre el tigre real, de fiera sangre caliente, que no conoce, y el simbólico, perteneciente a las palabras: «Al tigre de los símbolos he opuesto / El verdadero, el de caliente sangre, / El que diezma la tribu de los búfalos» (Borges, 1960, citado por Sariols Persson, 2012, p. 9)

Una reactualización de la metáfora gastada tiene lugar en el poema "Gorila", donde se invierte el parecido humano del gorila africano, al compararlo con el gorila americano, que vendría a ser el soldado o policía matón, ya que en la última estrofa se indica: «Lo adquirió / nuestro agente viajero en un cuartel / para el Gran Zoo.» (Guillén, 1984, p. 288).

Otro remozamiento metafórico se efectúa en el poema "El sueño", donde se diferencia el sueño como proceso biológico del sueño en sentido figurado como proyección de mundos o situaciones utópicas:

Esta mariposa nocturna

planea sobre nuestra cabeza

como el buitre sobre la carroña.

(El ejemplar

que aqui exhibimos es el sueño vulgar.)

Sin embargo,

la Dirección promete para fines de año,

o más pronto, tal vez,

remesas escogidas de sueños

así en hombre como en mujer.

Cinco cajas de moscas tsé-tsé

fueron pedidas anteayer.

(Guillén, 1984, p. 288)

La última estrofa desbarata las expectativas lectoras del sueño en sentido figurado prometido por la segunda estrofa. Las "moscas tse-tsé" son las moscas africanas chupadoras de sangre que al picar propagan diversas enfermedades, entre ellas, la enfermedad del sueño. Así las cosas, pasamos del sueño ordinario al sueño como enfermedad. El surrealismo de este poema estriba en la creación de asociaciones inesperadas ante el vaciamiento de significado de la palabra 'sueño'.

La segunda operación con la que Guillén logra homologar el tono con el cual describe los ejemplares de El gran zoo (1984) se efectúa con una frecuencia mucho mayor: aquellos entes que no son animales se animalizan o se antropomorfizan (prosopopeya). Se recurre a esta figura literaria en el poema "Guitarra":

Fueron a cazar guitarras

bajo la luna llena.

Y trajeron ésta, 
pálida, fina, esbelta,

ojos de inagotable mulata,

cintura de abierta madera.

Es joven, apenas vuela.

Pero ya canta

cuando oye en otras jaulas

aletear sones y coplas.

Los soneshombres y las coplasolas.

Hay en su jaula esta inscripción:

«Cuidado: sueña.»

(Guillén, 1984, p. 275)

Todas las palabras al final de los versos son graves, excepto el verso 12: 'inscripción'. Prevalece la rima asonante, como la combinación 'a-a' entre el verso 1 y 5: 'guitarra' y 'mulata'. En los versos 8 y 9 riman las palabras finales, 'canta', 'jaulas', mientras en los versos 10 y 11 la rima se establece entre las vocales 'o' y 'a' de las palabras finales. Se produce una rima interna entre los versos 9, 10 y 11, mediante las vocales 'o' y 'e': 'oye', 'sones', 'soneshombres'.

Por otro lado, se recurre al uso de los imperativos en infinitivo propio del lenguaje de los letreros (García Veitía, 1994). Al final del segundo y del tercer poema se coloca un aviso. El letrero del segundo poema, "El Caribe", advierte: «Cuidado: muerde.» refuerza el efecto del letrero del tercer poema, "Guitarra": "Cuidado: sueña.» (Guillén, 1984, pp. 274-275).

\section{EI tenor frente al espejo}

El poema "Tenor" prosigue con el tema de la música. Ahora bien, la aproximación que se propone aborda la división entre la cultura popular y la alta cultura. Entiéndase por "alta cultura" aquella producción simbólica consumida por las élites generadora de estatus social.

El problema de la representación se plantea en la primera estrofa del poema "Tenor": «Está el tenor en éxtasis / contemplando al tenor / del espejo, que es el mismo tenor / en éxtasis / que contempla al tenor.» (Guillén, 1984, p. 285). El espejo refleja la imagen del yo que "se pierde cuando se atrapa, [...] en la circularidad de ver y ser visto” (Enaudeau, 1999, p. 63). Entonces, ¿cuál de los dos es el tenor real?

Desde el punto de vista formal, esta estrofa presenta dos encabalgamientos, o frases que continúan en el verso siguiente. Ahora bien, lo interesante es que la voz lírica juega con dos partes móviles: 'del espejo' y 'en éxtasis'. Si 'del espejo' se une al verso anterior, formaría un endecasílabo; lo mismo sucede si se une 'en éxtasis' al verso siguiente. Ambas partes móviles refuerzan la circularidad entre lo representado y la representación, entre el tenor y su imagen en el espejo. 
La segunda estrofa practica una sátira de la dicotomía entre alta cultura y cultura popular que, ya por esos años, elaboraba la escuela de Birmingham (Inglaterra) desde los estudios culturales'

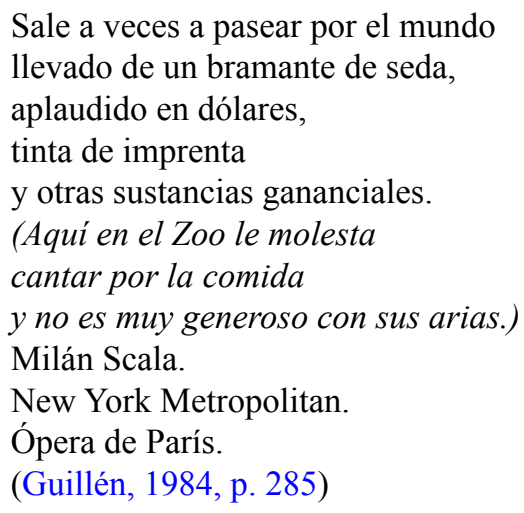

De acuerdo con Stuart Hall — quien formó parte de la escuela de Birminghamexisten representaciones que sustentan las estructuras de poder (citado por Walsh, 2010). Walsh plantea que "cuando las prácticas de representación se naturalizan, refuerzan los estereotipos y contribuyen a la subalternización de los sujetos" (2010, p. 217). La estrategia del yo lírico consiste en desnaturalizar tales prácticas. Nombra tres instancias de legitimación de la alta cultura, lo cual intensifica el efecto cómico: entre más alto sea su estatus, mayor será su rebajamiento.

\section{La Guerra Fría y la Carrera Espacial}

La Carrera Espacial formaba parte de la Carrera Armamentista entre la URSS y EE. UU. Ahora bien, la Carrera Espacial no solo consistía en ver cuál de las dos superpotencias ponía primero a un hombre en órbita o llegaba antes a Luna. Tampoco se reducía al dominio militar efectivo de la estratosfera. Implicaba una contienda de orden simbólico. La superioridad tecnológica equivalía a la superioridad ideológica del capitalismo o del comunismo.

Dos epigramas que se inscriben dentro de la temática de la Carrera Espacial son "Luna", cuyo último verso es «Sputniks y sonetos» y el de "La Osa Mayor", que indica al visitante del zoológico que fue cazada por «un sputnik» (Guillén, 1984, pp. 276, 284). Lo que apenas queda sugerido en ambos epigramas cobra mayor entidad en "Aviso Gran zoo de la Habana":

2 En relación con el origen de los estudios culturales, véase: Beverley, J. (1996). Sobre la situación actual de los estudios culturales. En J.A. Mazzotti y Juan Cevallos (Eds.) Asedios a la heterogeneidad cultural, libro de homenaje a Antonio Cornejo Polar. Pittsburg: Asociación Internacional de Peruanistas, pp. 455-474. 
Se avisa la llegada

de nuevos ejemplares, a saber:

La gran paloma fósil del jurásico,

en la que son visibles todavía

sus dos dispositivos lanzabombas.

Hay una colección de hachas atómicas,

máscaras rituales de forma antiaerolítica

y macanas de sílex radioactivo.

Finalmente un avión

(el tan buscado caza del plioceno)

que es una pieza de excepción.

(Guillén, 1984, pp. 286-287)

En el poema, suscrito por «El Director», prevalecen los endecasílabos. Contiene un epígrafe letrero: «Museo de prehistoria abierto al público — todos los días menos domingo-. Idiomas: español, inglés y ruso.» Este terceto en endecasílabos nos remite a la posición de Cuba en el mundo bipolar de la Guerra Fría ${ }^{3}$. La bipolaridad se refiere al hecho de que el mundo estaba dividido en dos grandes zonas de influencia: Occidente, que incluía a los países europeos que formaban parte de la OTAN bajo el dominio de Estados Unidos y los países del bloque socialista, como Cuba, liderado por la Unión Soviética.

Como si se tratara de un verdadero zoológico, los animales se encierran en jaulas y se describen mediante un lenguaje "científico o pseudo científico" (Morejón, 1994, p. 312). La paloma, símbolo de la paz, se convierte en un bombardero, lo que genera un oxímoron. Dicha imagen puede referirse a las bombas atómicas lanzadas por bombarderos estadounidenses contra las ciudades japonesas de Hiroshima y Nagasaki en agosto de 1945. Tales atrocidades ponen fin a las hostilidades del Pacífico durante la Segunda Guerra Mundial e inauguran la Era Atómica.

Desde el humor, el poema "Bomba atómica" alude de forma implícita a la crisis de los misiles en Cuba en 1962. El yo lírico advierte en los últimos dos versos: "Es un peligro bárbaro / este animal aquí" (Guillén, 1984, p. 289). Nikita Jrushchov y John F. Kennedy negociaron el retiro de los misiles estadounidenses que apuntaban a la Unión Soviética desde Turquía, a cambio de que los navíos soviéticos que transportaban misiles nucleares a Cuba emprendieran el viaje de regreso.

Durante las décadas de 1950 y 1960, los países latinoamericanos realizan ingentes esfuerzos por entrar en la modernidad. Se produce una violenta reordenación capitalista de la sociedad, pese a esfuerzos por fomentar un desarrollo autónomo,

3 El movimiento de los no alineados fue una iniciativa de un grupo de países del Tercer Mundo que buscaba mantenerse neutral ante esta polarización, apoyar los esfuerzos de descolonización en Asia, África y América, así como promover la cooperación entre sus miembros y el desarme nuclear. 
como el modelo de la sustitución de importaciones. Fenómenos como la migración de campesinos a las ciudades y la concentración de la riqueza en algunos países conduce a una vulnerabilidad social sin precedentes. Es la antesala de las dictaduras y los movimientos revolucionarios.

Pero no solo se criticaban valores basados en la racionalidad económica como la productividad. Hasta inicios de la década de 1960 se prohíben las explosiones atómicas con fines experimentales en la atmósfera. Habrá que esperar al final de la guerra de Vietnam para que se celebren los primeros tratados internacionales de reducción de armas nucleares, cuando las dos superpotencias del mundo bipolar, la URSS y EE. UU., acuerdan una política de distensión.

Los intelectuales y artistas comprometidos tomaron posición en contra de la carrera armamentista. Desde la corriente literaria del neobarroco, un grupo de escritores, entre ellos José Lezama Lima, cuestionó la capacidad de la literatura para representar el mundo extratextual. Al contrario de la antipoesía de Nicanor Parra, que aspiró a un lenguaje prosaico, los neobarrocos emplearon un lenguaje artificioso. Entra en crisis el realismo, crisis que será conjurada en la novelística por el realismo mágico de Cien años de soledad (1967). Lo que nos lleva a preguntarnos: ¿Cuál fue la reacción en el ámbito de la lírica?

La tendencia neovanguardista, que incluía a Nicolás Guillén, abordó temáticas filosóficas reservadas a la alta cultura desde la cultura popular. Esto implicaba la prevalencia del registro lingüístico coloquial sobre el registro lingüístico culto, así como cierta alusión a hechos históricos y referentes empíricos. Siempre y cuando estuvieran tales alusiones subordinadas al mundo de la imaginación poética de quien escribe.

¿Por qué, en el poema "Aviso Gran zoo de la Habana" la instancia lírica alude al Jurásico? Existía el temor de que el mundo se destruyera por una guerra nuclear en la lógica de la destrucción mutua entre Washington y Moscú. Por primera vez en la historia, la humanidad disponía de los medios para aniquilar a casi todos los seres vivos del planeta. Por consiguiente, la voz lírica crea una analogía entre la extinción de los dinosaurios hace 65 millones de años y la terrorífica posibilidad de que se desatara una Tercera Guerra Mundial que extinguiera el género humano.

\section{Conclusión}

En general, El gran zoo (1984) rechaza el enunciado hermético de las poéticas vanguardistas. La figura de «la Dirección» viene a ser un alter ego de la instancia lírica. El sujeto de la enunciación prefiere anclar su discurso en hechos históricos como la carrera espacial de la Guerra Fría. Desde el punto de vista formal, se 
privilegia el verso libre. A veces, la voz lírica opta por revertir metáforas gastadas, como el sueño o el tigre.

En otras ocasiones, se proponen metáforas con epítetos innovadores, como la guitarra adolescente. Sus ojos de mulata hacen referencia a la contaminación mutua de géneros literarios y formas musicales entre África, Europa y América.

El tratamiento igualitario a entes de diverso estatuto ontológico nos remite a una de las claves del poemario: el humor mediante el uso de la ironía. El humor desarticula las relaciones de poder y saber subyacentes a los estereotipos. Ello lo emparenta al Estravagario (1958) de Neruda.

Quien visita El gran zoo (1984) y mira al tenor, se encuentra ante un personaje narcisista. "El tenor" cuestiona el estatuto de la obra de arte al modo de las vanguardias. Simboliza el conflicto entre la alta cultura y la cultura popular. Cabe recordar la tendencia vanguardista de transgredir la separación tajante entre ambos sistemas.

¿De qué forma se parodia el discurso belicista del avance tecnológico? Se subvierte la dicotomía civilización y barbarie. La bomba atómica, sobre la cual Guillén escribe un poema homónimo, sería la cúspide del desarrollo tecnológico de la industria armamentista. No obstante, desde la perspectiva ética, los armamentos del siglo XX equivalen a fósiles de dinosaurios y utensilios de la Edad de Piedra.

Dicha estrategia se había adelantado en el poema "Lynch": «Lynch de Alabama. / Rabo en forma de látigo y pezuñas terciarias. Suele manifestarse / con una gran cruz en llamas.» (Guillén, 1984, p. 281). En este poema, el espécimen prehistórico es el esclavista.

Benítez Rojo (1998) afirma que la plantación constituye el hecho fundacional de la historia económica y sociopolítica de la región. En su análisis del poema "Los ríos", el crítico mencionado aclara que la oposición entre la poesía y la máquina ya estaba presente en West Indies Ltd. (1934) y en otros textos de la literatura cubana, como La zafra (1926) de Agustín Yáñez. Lo nuevo aquí, nos dice Benítez Rojo, es la jaula. En esto se aparta de la tradición de los bestiarios.

La jaula —o el acuario, en el caso del animal Caribe del poema homónimo- es frontera porosa, atravesada por el deseo y por relaciones de poder/saber no binarias; conjunto de diferencias imperfectas en constante transformación. 


\section{Referencias bibliográficas}

Benítez Rojo, A. (1998). La isla que se repite. Barcelona: Casiopea.

Enaudeau, C. (1999). La paradoja de la representación. Buenos Aires: Paidós.

García Veitía, M. (1994). El nuevo bestiario. En N. Morejón (Comp.) Recopilación de textos sobre Nicolás Guillén. La Habana y Santiago de Chile: Casa de las Américas y Mosquito Editores.

Guillén, N. (1984). El Gran Zoo. En Ángel Augier (Ed.) Nicolás Guillén. Las grandes elegías y otros poemas. Caracas: Ayacucho.

Morejón, N. (1994). Prólogo. En Morejón, N. (comp.) Recopilación de textos sobre Nicolás Guillén. La Habana y Santiago de Chile: Casa de las Américas y Mosquito Editores.

Pérez, A. J. (1992). Notas sobre las tendencias de la poesía post-vanguardista en Hispanoamérica. Hispania 75(1), marzo.

Sariols Persson, D. (2012). Un tigre, dos tigres. Lo antiguo y lo nuevo en los bestiarios de Jorge Luis Borges y Julio Cortázar. Cuadernos del CILHA, 13(16).

Szymoniak, E. (2011). Poemas al servicio de los grupos dominados: la identidad (afro) cubana y la poesía de Nicolás Guillén. Romanica Silesiana, (6).

Walsh, C. (2010). Estudios (inter) culturales en clave de-colonial. Tabula Rasa, (12), enero-junio. 
